Clinical biomarkers and management of post thrombotic syndrome

\author{
Antonio Biondi ${ }^{1}$, Giuseppe Strano ${ }^{1}$, Luca Ruggeri ${ }^{1}$, Salvatore Vadala ${ }^{1}$, Alessandro Tropea ${ }^{1}$, Francesco Basile ${ }^{1}$ \\ ${ }^{I}$ Section of General Surgery and Oncology, Department of General Surgery, University Medical School of Catania, Italy, \\ Ospedale Vittorio Emanuele Via Plebiscito, 628 - 95100 Catania, Italy
}

\title{
TABLE CONTENTS
}

1. Abstract

2. Introduction

2.1. Incidence of venous thromboembolism (VTE)

3. Methods

2.2. Frequency of the PTS after DVT

4. Clinical signs and pathophysiology

5. Diagnosis of PTS and clinical score system

6. Risk Factors

6.1. Age and sex

6.2. Body mass index (BMI)

6.3. Thrombophilia

6.4. Elevated D-dimer

7. Prevention of PTS

7.1. Elastic compression stockings

8. Treatment of PTS

9. Conclusion

10. Acknowledgments

11. References

\section{ABSTRACT}

The post-thrombotic syndrome (PTS) is a longterm complication of deep venous thrombosis (DVT) that is characterized by chronic, persistent pain, swelling and other signs in the affected limb. PTS is common, burdensome and costly. It is likely to increase in prevalence, since despite widespread use of and improvements in the efficacy of thromboprophylaxis, the incidence of DVT has not decreased over time. Preventing ipsilateral recurrence of DVT, by ensuring an adequate duration and intensity of anticoagulation for the initial DVT and by prescribing situational thromboprophylaxis after discontinuation of oral anticoagulants, is likely to reduce the risk of developing PTS. Pending the results of ongoing studies, stockings are recommended in patients with persistent symptoms or swelling after DVT. Future research should focus on standardizing criteria for PTS diagnosis, identification of DVT patients at high risk for PTS, and rigorously evaluating the effectiveness of stockings, thrombolysis, and venoactive drugs in preventing or treating PTS.

\section{INTRODUCTION}

Morbidity of patients with deep venous thrombosis (DVT) is high even years after the initial event $(1,2)$. Besides the risk of acute pulmonary embolism (PE), DVT is associated with a variety of symptoms, generally referred to as "post-thrombotic syndrome" (PTS), which restrict the quality of life $(2,3)$ ultimately leading to ulceration of the affected extremity (2-4-5).

The PTS is still not clearly defined, in fact there are several means of measuring and classifying chronic venous disease, based on clinical signs and symptoms. The most consented definition concerning this pathology says that is a long-term local complication after episode of DVT prevalently due by venous hypertension which results from valvular incompetence, outflow obstruction, calf muscle dysfunction.

To the best of our knowledge, only one study in Europe (10) and another study in the United States (11) 
have attempted to determine the costs associated with the entire range of long-term complications of DVT.

Results from an European study reported that after 15 years of follow-up, $35 \%$ of the patients with thrombosis and $57 \%$ of the controls were alive. Two hundred forty-two complications were reported among the patients with thrombosis, and 25 similar events were reported among the controls. The average expected present value of the health care cost of treating complications of thrombosis was estimated to be about $\$ 4659$ in the patients with thrombosis and $\$ 375$ in the controls. In controls, primary deep venous thrombosis cost about $\$ 6000$; thus, the additional long-term health care cost of post-thrombotic complications is about $75 \%$ of the cost of primary deep venous thrombosis (10). Results from an American study was too old (1977) in order to be taken in consideration with a new prospect about cost (11).

Although the clinical manifestations of PTS are well known, the quality-of-life and socioeconomic impacts of PTS have not been extensively documented, except for the most severe forms of the syndrome, such as venous leg ulcer $(12,13)$.

PTS is burdensome and costly to patients and society. At present, effective, evidence-based treatments for PTS are lacking, which is a source of difficulty and frustration for patients with PTS. Until effective treatments are found, prevention of PTS is the key to reducing its overall impact on patients and society. Preventing DVT recurrence is likely to reduce the risk and costs of PTS. Daily use of graduated ECS after DVT may reduce the risk of PTS. As of yet, there is no established role for thrombolysis in preventing PTS $(14,15)$.

The present review aims to analyze the large amount of informations on this issue trying to find some conclusions on a topic that is often unclear and confused.

\subsection{Incidence of venous thromboembolism (VTE)}

Since PTS is a direct consequence of DVT, its prevalence is influenced by the incidence of DVT. Despite advances in the prevention and treatment of VTE, populationbased studies from Europe and North America performed in each of the last three decades consistently show that the overall annual incidence of VTE is 1.0-1.6 per 1000 persons per year, with a per-person lifetime incidence of $2-5 \% .(18-19)$.

The apparent lack of decrease in VTE incidence over time could be the result of more complete case ascertainment in recent compared to older studies, but might also be due to aging of the population, exposure to more or new risk factors, and persistent under-utilization of appropriate thromboprophylaxis. There are approximately 200,000 250,000 new cases of VTE in the US per year (20). Thus, it is convincing that VTE represent a major global health problem.

\subsection{Frequency of the PTS after DVT}

Population-based studies demonstrate that reliable estimates of the incidence and prevalence of PTS are difficult to obtain. A recent retrospective cohort study evaluating cases of objectively diagnosed DVT or PE in which venous stasis syndrome subsequently developed (as diagnosed by a physician, or by objective evidence of venous valvular incompetence, or venous ulcer) reported that $16 \%$ of patients developed venous stasis syndrome after a mean follow-up of 7.3 years (20).

The cumulative rates were $7.3 \%$ at 1 year, $14.3 \%$ at 5 years, $19.7 \%$ at 10 years, and $26.8 \%$ at 20 years. The cumulative risk of ulcer by 20 years was $3.7 \%$.Using this same population base, it was shown that about one quarter of patients with venous stasis syndrome, or 170,000 new cases per year in the US, are attributable to prior VTE, i.e. represent bona fide PTS (21).

\section{METHODS}

To perform a systematic review of clinical studies that have examined the incidence, clinical features, risk factors and management of post-thrombotic syndrome.

Using combinations of keywords venous thrombosis, postphlebitic syndrome, thrombophlebitis, biomarkers, post-thrombotic syndrome, the MEDLINE database was searched for English language articles published. Retrieval and review of articles were restricted to clinical studies in humans that described long-term outcomes after objectively confirmed PTS.

\section{CLINICAL SIGNS AND PATHOPHYSIOLOGY}

The fundamental pathophysiological disturbance found in patients with severe leg symptoms or signs after deep vein thrombosis is sustained venous hypertension, which results from valvular incompetence, outflow obstruction, calf muscle dysfunction, or a combination of these (16). Even in patients who do achieve clot lysis, permanent damage to venous valves occurs frequently, conceivably via thrombus-induced activation of inflammation (17) or scarring associated with acute and resolving thrombosis, leading to valve incompetence (reflux). On physical examination, edema, telangiectasiae, hyperpigmentation, eczema, and varicose superficial (collateral) veins may be present (Table 1). In severe cases, there may be thickening and induration of the subcutaneous tissue around the ankle (lipodermatosclerosis) and evidence of healed or open ulceration $(13,22,23)$.

Valvular incompetence results from damage to venous valves at the time of the acute DVT, or during the process of vein recanalization after DVT. If recanalization is incomplete, venous outflow obstruction occurs and leads to the development of collateral circulation via the superficial and perforator veins, which may gradually become incompetent and varicose due to progressive dilation. Venous hypertension, the end result of these processes, leads to the appearance of telangiectasiae and venous ectasia, and causes capillary leakage of plasma proteins, erythrocytes and leukocytes, with resultant edema, tissue hypoxia and damage, and ultimately, in some cases, skin ulceration. 
Table 1. Clinical features of the PTS

\begin{tabular}{|l|l|}
\hline Leg symptoms & Signs \\
\hline Heaviness & Oedema \\
\hline Pain & Peri-malleolar Telangiectasiae \\
\hline Swelling & Venous ectasia \\
\hline Itching & Hyperpigmentation \\
\hline Cramps & Redness \\
\hline Paresthesia & Dependent cyanosis \\
\hline Bursting pain & Lipodermatosclerosis \\
\hline Symptom pattern & Healed ulcer \\
\hline Worse with activity, standing, walking & Open ulcer \\
\hline Better with rest, recumbency & \\
\hline & \\
\hline
\end{tabular}

Table 2. Clinical scales for the diagnosis of post-thrombotic syndrome (PTS)

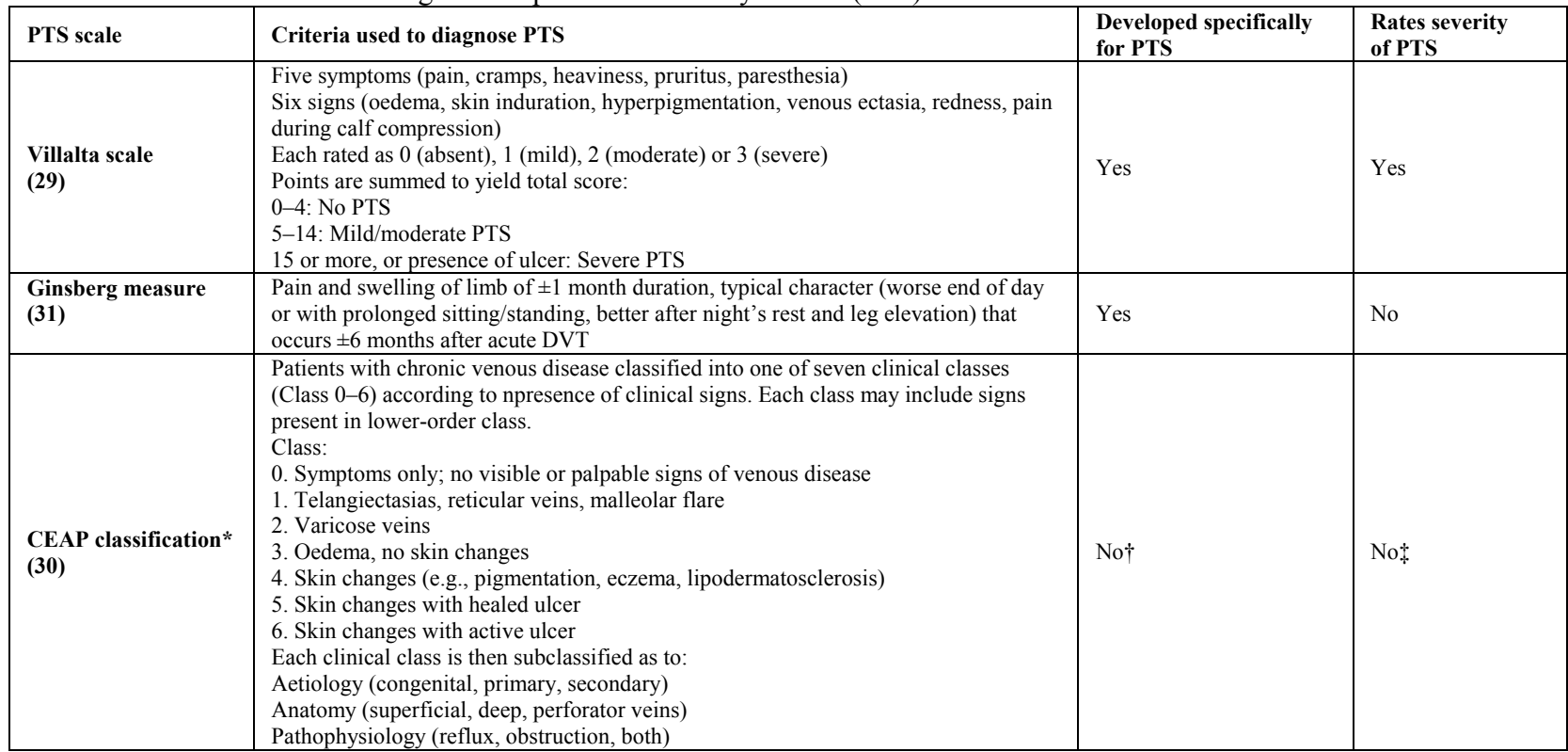

*CEAP: Clinical-Etiology-Anatomic-Pathophysiologic. Modifications of CEAP (Clinical Severity Score, Venous Segmental Disease Score) have been proposed [Rutherford et al, 2000 (50)], $†$ Developed for chronic venous disease in general, $\$$ Increasing CEAP class is intended to reflect increased severity of signs of chronic venous disease; symptoms and their severity are not considered, PTS $1 / 4$ postthrombotic syndrome

Reflux in the proximal veins, particularly the popliteal vein, appears to be important for the development of the clinical manifestations of PTS (26, 27). However, patients with objectively documented reflux after DVT may have no clinical evidence of PTS (28). Furthermore, the correlation between the severity of PTS and the site or severity of previous DVT or DVT-related hemodynamic or anatomic changes is unclear.

Pathophysiology of this syndrome involves the interplay of two processes: damage to delicate venous valves by the thrombus itself or by associated inflammatory mediators, which causes valvular reflux and residual venous obstruction because of incomplete thrombus clearance, which leads to impaired venous return. Both processes lead to increased venous pressure (venous hypertension), which results in reduced calf muscle perfusion, increased tissue permeability and the associated clinical manifestations of PTS (e.g. pain, effort intolerance, swelling) $(14,23,24)$.

\section{DIAGNOSIS OF PTS AND CLINICAL SCORE SYSTEM}

At baseline visit the physician examined the patient's legs and classified the clinical categories and severity of PTS using the different scoring systems.

Three clinical scales for the diagnosis of PTS have been developed (29-31) and are summarised in Table 2. These have been used to assess the presence and grade the severity of PTS in a number of clinical studies, including trials of therapies to prevent or treat PTS. However, none has undergone full evaluation of reliability, validity or responsiveness to change and their use for the routine clinical monitoring of DVT patients has not been assessed. Moreover, differences in the test characteristics of these measures could help to explain the differing rates of PTS that have been reported in long-term follow-up studies of patients with DVT.

The best known is the CEAP (Clinical, Etiologic, Anatomic, Pathophysiologic) classification, which 
Table 3. Last revision of CEAP, assessed in 2004 (33)

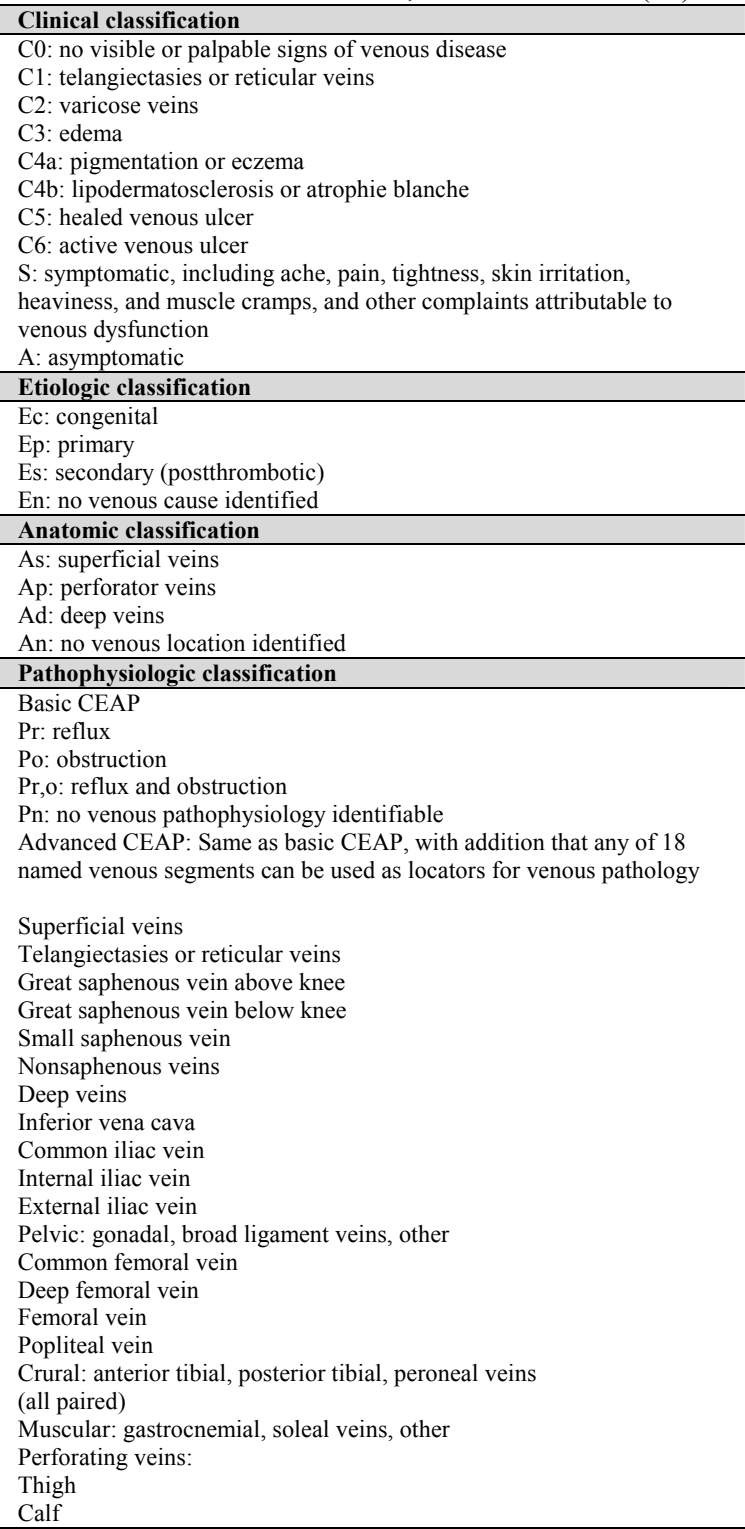

categorises patients into one of seven classes based on clinical signs, with modifiers that reflect the underlying cause (congenital, primary, or secondary to DVT), anatomic distribution (superficial, deep, or perforating veins), and pathophysiologic condition (reflux, obstruction, or both).(30,32)(Tab.3).

In patients with objectively confirmed DVT and a typical clinical presentation, PTS is usually the correct diagnosis. Documenting venous reflux by Doppler ultrasound or by photo or air plethysmography can help to confirm the diagnosis.(27,34,36,37). However, patients who have venous reflux on objective testing but who are asymptomatic do not have PTS.

Documenting prior DVT is important to confirm the diagnosis of PTS and to help guide patient management (e.g. appropriate
thromboprophylaxis).Evidence of deep vein reflux on Doppler ultrasound $(38,39)$ persistent obstruction, recanalized veins or collateral channels on venography, or outflow obstruction on plethysmography (40) reliably confirm previous proximal DVT. In one study, the combination of normal photoplethysmography and ultrasound reliably excluded prior proximal DVT.

\section{RISK FACTORS}

\subsection{Age and sex}

Two studies found that increasing age was associated with a higher risk of developing PTS (40,41), but other studies did not In one study, male sex was a weak risk factor for PTS. Overall, there do not appear to be consistent relationships between age or sex and the development of PTS.

\subsection{Body mass index (BMI)}

Results of prospective studies suggest that higher BMI is associated with a greater risk of PTS. Similarly found that BMI $>25$ was a significant independent predictor of PTS after proximal DVT. As obesity is a potentially modifiable risk factor, the role of weight reduction in the prevention or management of PTS merits evaluation as some type of cancer (41).

\subsection{Thrombophilia}

Inherited and acquired thrombophilic disorders increase the risk of developing a first episode of VTE (42) and in some studies, increased the risk of recurrent VTE (43). Some established risk factors for VT in general, such as older age, obesity, cancer in general, and stroke were not associated with VT in this study of medical inpatients (44).

\subsection{Elevated D-dimer}

This is a risk factor for first and recurrent DVT $(45,46)$. Elevated levels of D-dimer (defined as cut-off of $>500 \mathrm{ng} / \mathrm{ml}$ on an enzyme-linked immunosorbent assay), measured 3 weeks after withdrawal of oral anticoagulant therapy, were found to be a modest risk factor (OR 1.9, 95\% CI 1.0-3.9) for PTS in a recent study (7). These results require confirmation in large prospective studies.

\section{PREVENTION OF PTS}

Thromboprophylaxis is an effective means of preventing DVT, it is highly likely, by extrapolation, that use of thromboprophylaxis in high risk patients and settings as recommended in evidence-based consensus guidelines (47) will prevent cases of PTS. Further, while thromboprophylaxis is effective, its use does not eliminate the risk of VTE. Moreover, nearly $50 \%$ of VTE events occur unpredictably and are therefore not preventable with thromboprophylaxis. (14).

Catheter-directed thrombolysis, which involves direct delivery of a fibrinolytic drug into the clot via a catheter introduced within the thrombosed vein, may be safer and more effective than systemic Thrombolytic therapy and could hold promise as a means of preventing PTS (50). 
Table 4. Strategies for the prevention and management of PTS

\section{Prevention}

Prevent index DVT with the use of thromboprophylaxis in high-risk patients and settings as recommended in evidence-based consensus guidelines.

Prevent recurrent ipsilateral DVT by providing anticoagulation of appropriate intensity and duration for the initial DVT and by targeted use of appropriate

thromboprophylaxis if long-term anticoagulation is discontinued.

Use of knee-length, $30-40 \mathrm{~mm} \mathrm{Hg}$ ECS elastic compression stockings for up to 2 years after DVT; optimal duration uncertain

The role of thrombolysis for the prevention of PTS is not yet established. Catheter-directed thrombolysis requires further evaluation in properly designed trials

before it is endorsed as being

effective in reducing the risk of PTS

Management

Elastic compression stockings reduce odema and may improve PTS symptoms.

Intermittent pneumatic compression units are effective for severe symptomatic PTS

Venoactive agents, such as aescin (e.g. as found in horse chestnut) or rutosides, may offer short term improvement of PTS symptoms; large controlled trials

addressing long-term effectiveness and safety are needed.

Compression therapy, skin care and topical dressings are used to treat venous ulcers.

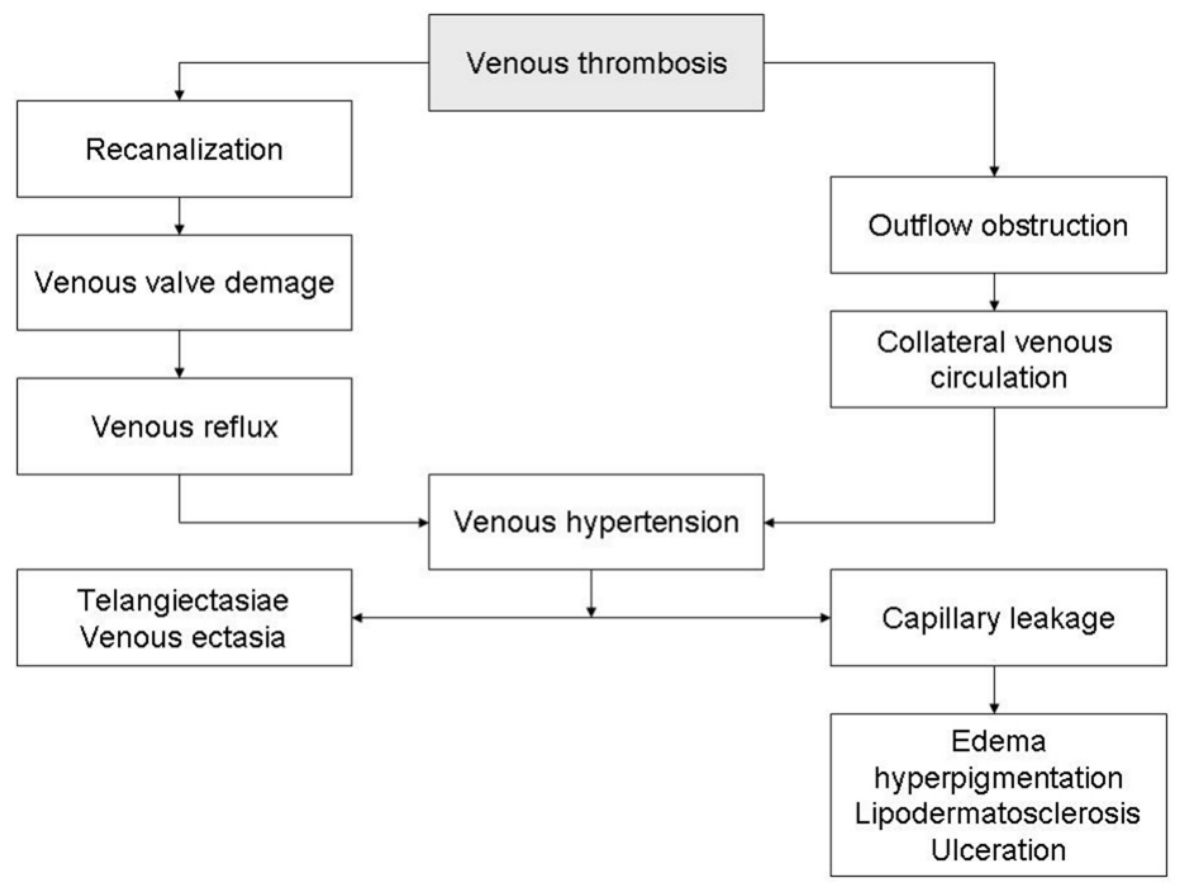

Figure 1. Pathophysiology of PTS.

The routine use of thrombolysis to prevent PTS in patients with acute DVT cannot be recommended at present. Large, adequately powered, randomized controlled trials of standard anticoagulation vs. catheter-directed thrombolysis (which may be safer and more effective than systemic therapy (52) are required to determine whether this form of thrombolysis is effective in preventing PTS and safe.

\subsection{Elastic compression stockings}

Graduated elastic compression stockings (ECS) decrease oedema and improve tissue microcirculation (49). Knee-length and thigh-length ECS appear to have equal physiological effects, but the former are easier to apply and more comfortable (51). A recent meta-analysis that pooled these three studies reported an overall $54 \%$ relative risk reduction in PTS with use of ECS (53).

\section{TREATMENT OF PTS}

Clinicians often prescribe physical compression methods to counteract increased venous pressure. ECS on an as-needed basis may reduce swelling in some patients with PTS (54) and should be tried. However, their treatment benefit has not been definitively shown in the setting of PTS and is primarily extrapolated from studies of patients with chronic venous disease (55).Indeed, a recent Cochrane review (53) concluded that there is no evidence to support the use of ECS to treat PTS, and while intermittent pneumatic compression units may be of benefit for the management of severe, intractable PTS symptoms or severe oedema, they are cumbersome, expensive and there are no data on their long term effects. Finally, surgical treatments for PTS, such as venous valve repair or venous bypass have been evaluated primarily in small patient series at single, specialised centres and appear to be of limited value (56).

The recommendations about the duration and type of long term treatment in patients with a first episode of VTE are summarized in. Although VKA is mostly used for long-term treatment, LMWH is preferred in patients with cancer (57).The endovenous 980-nm diode laser 
surgery is a safe and effective, cosmetically preferential procedure while a long-term follow-up is being awaited (58).

\section{CONCLUSION}

PTS leads to chronic and severe morbidity. It's best treatment remains prevention and early identification of risk factors, prevention of DVT, and aggressive management of DVT. In established DVT patients, anticoagulation, compression, exercise, and skin care measures are needed in order to prevent DVT recurrence and long-term sequellae such as PTS. Post-thrombotic syndrome is burdensome and costly to patients and society. Until effective treatments are found, prevention of PTS is the key to reducing its overall impact on patients and society.

Most physicians believe that ECS are useful for preventing PTS and for managing venous symptoms, many do not routinely prescribe them, and there is considerable variation in practice regarding the timing of initiation of ECS, duration of therapy, and compression strength. On the other hand, DVT patients appear to be willing to purchase ECS despite their cost, tolerate them well, and most are willing to wear them daily. As of yet, there is no established role for thrombolysis in preventing PTS.

With evalution of new anticoagulants there is no doubt that in the near future the treatment of patients with VTE will become more patient friendly, effective, safe and evidence based.

\section{ACKNOWLEDGMENTS}

Author A. Biondi and G. Strano equaly contributed to this article. Sources of financial support: 1) Departed of General Surgery - University of Catania; 2) Postgraduate Research Degrees on "Physiopathology pre and post-operative surgery for election and the emergency" - University of Catania.

\section{REFERENCES}

1. Prandoni P, Lensing AWA, Cogo A, Cuppini S, Villata S, Carta M, Cattelan AM. The longterm clinical course of acute deep venous thrombosis. Ann Intern Med; 125:1-7 (1996)

2. Rutherford RB. Pathogenesis and pathophysiology of the post-thrombotic syndrome. Clin Implic 1996;9:21-5.

3. BalbariniA, RugolottoM,Buttitta F, Mariotti R, Strata G, Mariani M. Deep venous thrombosis: epidemiologic, diagnostic and therapeutic aspects. Cardiologia; 43:605-15 (1998)

4. Mayer W, Partsch H. Clinical features in postthrombotic syndrome. Wi Kli Wo 1994;(10/11):213-6.

5. S. Ziegler, M. Schillinger, T.H. Maca and E. Minar . Postthrombotic Syndrome After Primary Event of Deep Venous Thrombosis 10 to 20 Years Ago. Thrombosis Research 101 23-33,(2001)
6. Kahn, S.R. \& Ginsberg, J.S. Relationship between deep venous thrombosis and the postthrombotic syndrome. Archives of Internal Medicine, 164, 17-26 (2004)

7. Stain, M., Schonauer, V., Minar, E., Bialonczyk, C., Hirschl, M., Weltermann, A., Kyrle, P.A. \& Eichinger, S. The post thrombotic syndrome: risk factors and impact on the course of thrombotic disease. Journal of Thrombosis and Haemostasis, 3, 2671-2676 (2005)

8. Schulman, S., Lindmarker, P., Holmstrom, M., Larfars, G., Carlsson, A., Nicol, P., Svensson, E., Ljungberg, B., Viering, S., Nordlander, S., Leijd, B., Jahed, K., Hjorth, M., Linder, O. \& Beckman, M. Post-thrombotic syndrome, recurrence, and death 10 years after the first episode of venous thromboembolism treated with warfarin for 6 weeks or 6 months. Journal of Thrombosis and Haemostasis, 4, 734-742 (2006)

9. Kahn, S.R., Hirsch, A. \& Shrier, I. Effect of postthrombotic syndrome on health-related quality of life after deep venous thrombosis. Archives of Internal Medicine, $162,1144-1148$ (2002)

10. Bergqvist D, Jendteg S, Johansen L, et al. Cost of longterm complications of deep venous thrombosis of the lower extremities: an analysis of a defined patient population in Sweden. Ann Intern Med;126:454-7 (1997)

11. O'Donnell TF, Browse NL, Burnand KG, Thomas ML. The socioeconomic effects of an iliofemoral venous thrombosis. J Surg Res;22:483-8 (1977)

12. Ruckley CV. Socioeconomic impact of chronic venous insufficiency and leg ulcers. Angiology;48:67-9 (1997)

13. Bernardi E, Prandoni P. The post-thrombotic syndrome. Curr Opin Pulm Med;6:335-42 (2000)

14. Kahn SR. The post-thrombotic syndrome: progress and pitfalls. Br J Haematol. Aug;134(4):357-65 (2006) Epub Jul 4 (2006)

15. Joseph A. Caprini, MD, Marc F. Botteman, MSc, Jennifer M. Stephens, PharmD, Vijay Nadipelli MS, Mary M. Ewing, MBA, Suzanne Brandt, BA, Chris L. Pashos, $\mathrm{PhD}$, Alexander T. Cohen, MD. Economic Burden of Long-Term Complications of Deep Vein Thrombosis after Total Hip Replacement Surgery in the United States. Value Health. Jan-Feb;6(1):59-74 (2003)

16. Criado E. Laboratory evaluation of the patient with chronic venous insufficiency. In: Rutherford $R B$, ed. Vascular surgery. 4th ed Philadelphia, PA: W.B. Saunders company,:1771-1785 [chapter 133] (1995)

17. Roumen-Klappe, E., der Heijer, M., van Uum, S., van der Ven-Jongekrijg, J., van der Graaf, F. \& Wollersheim, H. Inflammatory response in the acute phase of deep vein thrombosis. Journal of Vascular Surgery, 35, 701-706 (2002) 
18. Coon WW, Willis PW, Keller JB. Venous thromboembolism and other venous disease in the Tecumseh community health study. Circulation: 839-846 (1973)

19. Heit JA, Silverstein MD, Mohr DN et al. The epidemiology of venous thromboembolism in the community. Thromb Haemost; 86: 452-463 (2001)

20. Mohr DN, Silverstein MD, Heit JA, Petterson TM, O'Fallon WM, Melton III LJ. The venous stasis syndrome after deep vebous thrombosis or pulmonary embolism: a population based study. Mayo Clin Proc; 75(III): 1249$1256(2000)$

21. Heit JA, Rooke TW, Silverstein MD et al. Trends in the incidence of venous stasis syndrome and venous ulcer: a 25-year populationbased study. J Vasc Surg; 33: 10221027 (2001)

22. Kahn SR, Solymoss S, Lamping DL, Abenhaim L. Long-term outcomes after deep vein thrombosis: postphlebitic syndrome and quality of life. J Gen Intern Med; 15: 425-429 (2000)

23. Hopkins NF, Wolfe JH. ABC of vascular diseases. Deep venousinsufficiency and occlusion. $B M J ; 304$ : 107$110(1992)$

24. Ackroyd JS, Browse NL. The investigation and surgery of the post-thrombotic syndrome. J Cardiovasc Surg (Torino); 27:5-16 (1986)

25. Negus D. The post-thrombotic syndrome. Ann $R$ Coll Surg Engl; 47: 92-105 (1970)

26. Markel A, Manzo RA, Bergelin RO, Strandness DE. Valvular reflux after deep vein thrombosis: incidence and time of occurrence. J Vasc Surg; 15: 377-382 (1992)

27. Franzeck UK, Schalch I, Bollinger A. On the relationship between changes in the deep veins evaluated by duplex sonography and the potthrombotic syndrome 12 years after deep vein thrombosis. Thromb Haemost; 77: 1109-1112 (1997)

28. Milne AA, Stonebridge PA, Bradbury AW, Ruckley $\mathrm{CV}$. Venous function and clinical outcome following deep vein thrombosis. Br J Surg; 81: 847-849 (1994)

29. Villalta, S., Bagatella, P., Piccioli, A., Lensing, A., Prins, M. \& Prandoni, P. Assessment of validity and reproducibility of a clinical scale for the post-thrombotic syndrome (abstract) Haemostasis, 24, 158a (1994)

30. Porter, J.M., Moneta, G.L., \& An International Consensus Committee on Chronic Venous Disease Reporting standards in venous disease: An update. Journal of Vascular Surgery, 21, 635-645 (1995)

31. Ginsberg, J.S., Gent, M., Turkstra, F., Buller, H.R., MacKinnon, B., Magier, D. \& Hirsh, J. Postthrombotic syndrome after hip or knee arthroplasty. Archives of Internal Medicine, 160, 669-672 (2000)

32. Porter JM, Rutherford RB, Clagett GP et al. Reporting standards in venous disease. J Vasc Surg; 8: 172-181 (1988)

33. B . Eklöf, R . Rutherford, J . Bergan , P . Carpentier, P . Gloviczki, R . Kistner, M . Meissner, G . Moneta, K . Myers , F . Padberg. Revision of the CEAP classification for chronic venous disorders: Consensus statement . J Vasc Surg. Dec;40(6):1248-52 (2004)

34. Franzeck UK, Schalch I, Jager KA, Schneider E, Grimm J, Bollinger A. Prospective 12-year follow-up study of clinical and hemodynamic sequelae after deep vein thrombosis in low-risk patients (Zurich Study) Circulation; 93: 74-79 (1996)

35. Kakkar VV, Lawrence D. Hemodynamic and clinical assessment after therapy for acute deep vein thrombosis. Am J Surg; 153: 54-63 (1985)

36. Killewich LA, Martin R, Cramer M, Beach KW, Strandness Jr. DE. An objective assessment of the physiologic changes in the postthrombotic syndrome. Arch Surg; 120: 424-426 (1985)

37. Meissner MH, Caps MT, Zierler BK et al. Determinants of chronic venous disease after acute deep venous thrombosis. J Vasc Surg; 28: 826-833 (1998)

38. Ginsberg JS, Shin A, Turpie AG, Hirsh J. Detection of previous proximal venous thrombosis with Doppler ultrasonography and photoplethysmography. Arch Intern Med; 149: 2255-2257 (1989)

39. Villalta S, Prandoni P, Cogo A et al. The utility of non-invasive tests for detection of previous proximalvein thrombosis. Thromb Haemost; 73: 592-596 (1995)

40. Prandoni, P., Lensing, A.W.A., Prins, M.H., Frulla, M., Marchiori, A., Bernardi, E., Tormene, D., Mosena, L., Pagnan, A. \& Girolami, A. Below-knee elastic compression stockings to prevent the post-thrombotic syndrome: a randomized, controlled trial. Annals of Internal Medicine, 141, 249-256 (2004)

41. Van Dongen, C.J., Prandoni, P., Frulla, M., Marchiori, A., Prins, M.H. \& Hutten, B.A. Relation between quality of anticoagulant treatment and the development of the postthrombotic syndrome. Journal of Thrombosis and Haemostasis, 3, 939-942 (2005)

42. Bauer, K. (2005) Hypercoagulable States. Hematology, 10 Suppl 1, 39.

43. Palareti, G. \& Cosmi, B. Predicting the risk of recurrence of venous thromboembolism. Current Opinion in Hematology, 11, 192-197 (2004)

44. Zakai N. A., Wright J. and Cushman M. Risk factors for venous thrombosis in medical inpatients: validation of a 
thrombosis risk score. Journal of Thrombosis and Haemostasis, 2: 2156-2161 (2004)

45. Cushman, M., Folsom, A.R., Wang, L., Aleksic, N., Rosamond, W.D., Tracy, R.P. \& Heckbert, S.R. Fibrin fragment D-dimer and the risk of future venous thrombosis. Blood, 101, 1243-1248 (2003)

46. Cosmi, B., Legnani, C., Cini, M., Guazzaloca, G. \& Palareti, G. D-dimer levels in combination with residual venous obstruction and the risk of recurrence after anticoagulation withdrawal for a first idiopathic deep vein thrombosis. Thrombosis and Haemostasis, 94, 969-974 (2005)

47. Geerts, W.H., Pineo, G.F., Heit, J.A., Bergqvist, D., Lassen, M.R., Colwell, C.W. \& Ray, J.G. Prevention of venous thromboembolism: the Seventh ACCP Conference on Antithrombotic and Thrombolytic Therapy. Chest, 126, 338S-400S (2004)

48. Comerota, A.J., Throm, R.C., Mathias, S.D., Haughton, S. \& Mewissen, M. Catheter-directed thrombolysis for iliofemoral deep venous thrombosis improves healthrelated quality of life. Journal of Vascular Surgery, 32, 130-137 (2000)

49. Pierson, S., Pierson, D., Swallow, R. \& Johnson, G.J. Efficacy of graded elastic compression in the lower leg. JAMA, 249, 242-243 (1983)

50. Rutherford RB, Padberg FT, Comerota AJ, Kistner RL, Meissner MH, Moneta GL. Venous severity scoring: an adjunct to venous outcome assessment. J Vasc Surg; 31: 1307-1312 (2000)

51. Benko, T., Cooke, E.A., McNally, M.A. \& Mollan, R.A. Graduated compression stockings: knee length or thigh length. Clinical Orthopaedics and Related Research, 383, 197-203 (2001)

52. Mewissen MW, Seabrook GR, Meissner MH, Cynamon J, Labropoulos N, Haughton SH. Catheter-directed thrombolysis for lower extremity deep venous thrombosis: report of a national multicenter registry. Radiology; 211: 39-49 (1999)

53. Kolbach, D., Sandbrink, M., Neumann, H. \& Prins, M. (2003b) Compression therapy for treating stage I and II (Widmer) post-thrombotic syndrome. The Cochrane Database of Systematic Reviews, Issue 4. Art. No.: CD004177. DOI: 10.1002/14651858. CD004177 (2003)

54. Prandoni, P. Elastic stockings, hydroxyethylrutosides or both for the treatment of post-thrombotic syndrome. Thrombosis and Haemostasis, 93, 183-185 (2005)

55. Kurz X, Kahn SR, Abenhaim L, Clement D, Norgren L, Baccaglini U, Berard A, Cooke JP, Cornu-Thenard A, Depairon M, Dormandy JA, Durand-Zaleski I, Fowkes GR, Lamping DL, Partsch H, Scurr JH, Zuccarelli F. Chronic venous disorders of the leg: epidemiology, outcomes, diagnosis and management. Summary of an evidence-based report of the VEINES task force. Venous Insufficiency Epidemiologic and Economic Studies. Int Angiol. Jun;18(2):83-102. Review (1999)

56. Eklof, B.G., Kistner, R.L. \& Masuda, E.M. Venous bypass and valve reconstruction: long term efficacy. Vasc Med, 3, 157-164 (1998)

57. Buller HR, Sohne M, Middeldorp S. Treatment of venous thromboembolism. J Thromb Haemost; 3: 1554-60 (2005)

58. Park SJ, Yim SB, Cha DW, Kim SC, Lee SH. Endovenous Laser Treatment of the Small Saphenous Vein with a 980-nm Diode Laser: Early Results. Dermatol Surg;34:517-524 (2008)

Key Words: Deep venous thrombosis, Upper extremity, Post-thrombotic syndrome, Biomarkers, Review

Send correspondence to: Antonio Biondi, Section of General Surgery and Oncology, Department of General Surgery, University Medical School of Catania, Italy, Ospedale Vittorio Emanuele Via Plebiscito, 628,95100 Catania, Italy, Tel.: 390957435151, Fax: 39095457345, Email: biondian@tin.it

http://www.bioscience.org/current/vol2E.htm 